\title{
Extract from mistletoe, Viscum album L., reduces Hsp27 and 14-3-3 protein expression and induces apoptosis in $\mathrm{C} 6$ rat glioma cells
}

\author{
E.Ö. Uçar ${ }^{1}$, N. Arda ${ }^{1}$ and A. Aitken ${ }^{2}$ \\ ${ }^{1}$ Department of Molecular Biology and Genetics, Faculty of Science, \\ Istanbul University, Vezneciler-Istanbul, Turkey \\ ${ }^{2}$ School of Biological Sciences, Darwin Building, University of Edinburgh, \\ Edinburgh, Scotland, UK \\ Corresponding author: E.Ö. Uçar \\ E-mail: evrenonay@istanbul.edu.tr
}

Genet. Mol. Res. 11 (3): 2801-2813 (2012)

Received February 24, 2012

Accepted June 13, 2012

Published August 24, 2012

DOI http://dx.doi.org/10.4238/2012.August.24.5

\begin{abstract}
Extracts of mistletoe (Viscum album) are intensively used in complementary medicine, but their mechanisms are not fully understood in most cases, and the effects on metabolism have not been investigated in detail. However, some biologically active natural products are well known to provoke unexpected cellular responses. They reduce overexpression of heat shock proteins (Hsps) in cancer cells. The aim of the current study was to determine whether methanolic extract of $V$. album, which possesses antioxidant activity, has an effect on expression levels of Hsp27 and 14-3-3 proteins in a C6 glioma cell line. For the first time, the apoptosis-inducing effect of this extract was also determined via caspase- 3 activation in the cells. Overexpression of Hsps was induced by heat shock at $42^{\circ} \mathrm{C}$ for $1 \mathrm{~h}$. Expression levels of Hsp27 and 14-3-3 proteins were determined using Western blot analysis. The apoptosis-inducing effect was also evaluated via caspase-3 activation in C6 glioma cells. Pretreatment of the cells with a nontoxic dose $(100 \mu \mathrm{g} / \mathrm{mL})$ of $V$. album extract before heat shock significantly reduced expression levels of Hsp27 (73\%) and 14-3-3ß (124\%), 14-
\end{abstract}


$3-3 \gamma(23 \%)$, and $14-3-3 \zeta(84 \%)$ proteins. Pretreatment with the extract before heat shock increased apoptosis via caspase-3 activation (60\%) in C6 glioma cells. This result suggested that the methanolic extract of $V$. album downregulates expression of Hsp27 and 14-3-3 chaperone proteins and induces apoptosis, which warrants further exploration as a potential bioactive compound for cancer therapy.

Key words: Viscum album; Heat shock protein 27 (Hsp27); Apoptosis; 14-3-3 Proteins; Glioma; Antioxidant

\section{INTRODUCTION}

Mistletoe, Viscum album L. ssp album (Loranthaceae, Viscaceae), which grows on various plants and especially on deciduous trees, has been widely used for centuries in both traditional and complementary medicine (Ernst et al., 2003). Various extracts prepared from several parts of the plant have anticancer, antiviral, antioxidant, and apoptosis-inducing effects (Büssing and Schietzel, 1999; Zarkovic et al., 2001; Karagöz et al., 2003; Önay-Uçar et al., 2006).

All organisms respond to environmental and physiological stress at the molecular level by synthesizing heat shock proteins (Hsps), also called stress proteins. Some of these proteins are constitutively expressed and others are inducible. Hsps mediate the refolding or degradation of stress-damaged proteins, thus protecting cells from potential deleterious effects and promoting cell recovery. A number of studies have shown that some Hsps are induced in specific tumor cells (Ciocca and Calderwood, 2005; Didelot et al., 2007). Tumor cells are well known to be resistant to cell death, and Hsps have been suggested to be responsible for this resistance by protecting the cells from apoptosis (Garrido et al., 2006; Arrigo, 2007). This involvement may explain the fact that overexpression of Hsps in tumor cells indicates poor prognosis and resistance to chemotherapy or radiotherapy (Garrido et al., 2006; Didelot et al., 2007). Thus, decreasing the Hsp level in cancer cells would be beneficial for treatment.

The small Hsp27 $(27 \mathrm{kDa})$ is a molecular chaperone in cellular responses against a variety of stresses, such as heat shock, toxicants, and oxidative stress (Ciocca and Calderwood, 2005). In addition, Hsp27 can act at multiple control points along apoptotic pathways (Garrido et al., 2006; Arrigo, 2007). Overexpression of Hsp27 has been demonstrated in some cancers and can be used as a biomarker (Ciocca and Calderwood, 2005; Chen et al., 2010). High levels of Hsp27 have been detected in head and neck squamous cell carcinoma, hepatocellular carcinoma, and prostate cancer (Andrieu et al., 2010; Chen et al., 2010; Zhu et al., 2010). In addition, Hsp27 level is reportedly increased in brain tumors and glioma (Zhang et al., 2003; Graner and Bigner, 2005). A number of studies have shown that increased Hsp27 in cancer cells is related to poor prognosis and resistance to therapy (Didelot et al., 2007; Zhu et al., 2010).

The 14-3-3 proteins are a family of small (28-33 kDa), abundant, acidic dimeric proteins that are widely expressed in all eukaryotic cells. Seven isoforms $(\beta, \gamma, \varepsilon, \eta, \sigma, \theta / \tau$, and $\zeta)$ have been identified in mammals. Isoform-specific expression and function in various types of normal and tumor cells and tissues have been defined (Aitken, 2006). The 14-3-3 isoforms are involved in the regulation of most cellular processes, including signal transduction, protein synthesis, folding and degradation, cell cycle control, cytoskeletal rearrangement, cellular trafficking, DNA replication, apoptosis, and survival (van Hemert et al., 2001). Because heat 
shock stress induces upregulation of some isoforms via a process mediated by heat shock transcription factor, these proteins are considered Hsps (Yano et al., 2006). More important, the 14-3-3 proteins regulate various oncogenic and tumor suppressor genes, which indicates that 14-3-3 isoforms are potential molecular markers for cancer diagnosis and monitoring (Hermeking, 2003).

Although 14-3-3 isoforms are ubiquitously expressed, they are particularly abundant in the brain, comprising about $1 \%$ of the total soluble protein, and in primary human nervous

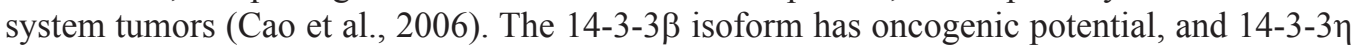
is a chaperone-like protein. They are found abundantly in human astrocytomas, which may be a common mechanism for evading apoptosis (Cao et al., 2008). The 14-3-3 $\beta, \eta, \sigma$, and $\zeta$ proteins are suggested to play important roles in the tumorigenesis of human glioma (Liang et al., 2009). The elevated expression of 14-3-3 $\sigma$ causes resistance to anticancer drugs and radiation in breast cancer cell lines and human pancreatic cancers (Li et al., 2010).

Although some reports show that Hsp27 and 14-3-3 proteins have been upregulated in primary nervous system tumors, human astrocytomas, gliomas, and brain tumors (Zhang et al., 2003; Cao et al., 2006, 2008; Liang et al., 2009), the expression status of these proteins has not been examined in C6 glioma cells. This study was performed with the aim of determining the effect of $V$. album methanolic extract on the expression levels of Hsp27 and 14-3-3 proteins and evaluating its apoptotic effect via caspase-3 activation in C6 glioma cells.

\section{MATERIAL AND METHODS}

\section{Chemicals and reagents}

Anti-Hsp27 monoclonal antibody and goat anti-mouse immunoglobulin G (horseradish peroxidase conjugated) antibody were purchased from Stressgen Biotechnologies Corp. (Canada). Polyclonal primary antibodies of $14-3-3$ proteins $(\beta, \varepsilon, \gamma, \eta$, and $\zeta)$ and secondary antibodies were raised in rabbits (Martin et al., 1993). An antibiotic-antimycotic mixture containing $100 \mathrm{U} / \mathrm{mL}$ penicillin, $100 \mu \mathrm{g} / \mathrm{mL}$ streptomycin, and $0.25 \mu \mathrm{g} / \mathrm{mL}$ amphotericin B was purchased from Invitrogen (USA). An ECL-Plus Western Blotting Detection system was purchased from Amersham (USA). A caspase-3 colorimetric activity assay kit was purchased from Chemicon (USA). Unless otherwise stated, reagents were obtained from Sigma Aldrich (USA).

\section{Plant material}

V. a. ssp album plants growing on lime trees (Tilia argentea Desf. ex DC.) in northern Istanbul were harvested in July 2008, and a voucher specimen was deposited in the Herbarium of Istanbul University (ISTF No. 37486). Fresh leaves were picked and washed with tap water and distilled water. Then, they were rubbed, cut into small pieces, weighed, and used immediately or stored at $-20^{\circ} \mathrm{C}$ until use.

\section{Extract preparation}

The extract was prepared as described elsewhere (Önay-Uçar et al., 2006). Twenty grams of fresh leaves was macerated in $160 \mathrm{~mL}$ methanol in an incubatory shaker $(150 \mathrm{rpm}$, 
$25^{\circ} \mathrm{C}$ ) for 2 days with refreshed solvent at the end of the first day. The plant residues were removed, and filtrates were combined and evaporated to dryness under vacuum. The stock solution of methanolic extract was dissolved in dimethyl sulfoxide at a $40 \mathrm{mg} / \mathrm{mL}$ concentration, and various dilutions were used in the assays.

\section{Cell culture}

C6 rat glioma cells were provided by Professor Ayhan Bilir (Department of Histology and Embryology, Faculty of Medicine, Istanbul University) and cultured in monolayer culture in Dulbecco's modified Eagle's medium/nutrient medium F-12 Ham (DMEM-F12) supplemented with $10 \%(\mathrm{v} / \mathrm{v})$ fetal bovine serum and antibiotic-antimycotics at $37^{\circ} \mathrm{C}$ in a $5 \%$ $\mathrm{CO}_{2}$ humidified incubator. Cells in the flasks were harvested using $0.2 \%$ Trypsin and $0.04 \%$ ethylenediaminetetraacetic acid. Trypsinization was carried out for $1 \mathrm{~min}$ and stopped with the addition of DMEM-F12. After transferring the suspension to a Falcon tube, the cells were precipitated via centrifugation ( $3000 \mathrm{~g}$ at room temperature) and resuspended in culture medium. Following Trypan blue exclusion assay, the cells $\left(1 \times 10^{5}\right.$ cells $\left./ \mathrm{mL}\right)$ with $100 \%$ vitality were plated in a culture flask containing $5 \mathrm{~mL}$ DMEM-F12 and grown in a humidified atmosphere containing $5 \% \mathrm{CO}_{2}$ at $37^{\circ} \mathrm{C}$.

\section{Cytotoxicity test}

The cytotoxic activity of the extract was tested using a 3-(4,5-dimethylthiazol-2-yl) 2, 5-diphenyl tetrazolium bromide (MTT) assay, with minor modifications (Hamad et al., 2010). The cells were maintained on 96-well plates (each well contained $200 \mu \mathrm{L}$ cell suspension at a density of $1 \times 10^{5}$ cells $/ \mathrm{mL}$ ). After reaching confluence (1 day later), the cells were treated with increasing concentrations $(5-750 \mu \mathrm{g} / \mathrm{mL})$ of $V$. album extract diluted with DMEM-F12. After cell growth for $48 \mathrm{~h}$ at $37^{\circ} \mathrm{C}$ in a humidified $5 \% \mathrm{CO}_{2}$ atmosphere, the adherent cells were washed with phosphate-buffered saline, then $10 \mu \mathrm{L} 5 \mathrm{mg} / \mathrm{mL}$ MTT stock solution, and $90 \mu \mathrm{L}$ phosphate-buffered saline buffer was added to each well, and the plates were further incubated at $37^{\circ} \mathrm{C}$ for $4 \mathrm{~h}$. At the end of this period, the supernatants were discarded and $200 \mu \mathrm{L}$ DMSO was added to each well to solubilize the water-insoluble purple formazan crystals. Absorbance was measured at 570 and $690 \mathrm{~nm}$ in a microplate reader ( $\mu$ Quant, Bio-Tek Instruments, Inc., Highland Park, IL, USA). The cell viability was calculated using the following equation:

$$
\text { Cell viability }(\%)=\left(\mathrm{A}_{\text {sample }} / \mathrm{A}_{\text {controo }}\right) \times 100
$$

(Equation 1)

\section{Induction of Hsps through heat shock treatment}

Because the level of Hsps was too low to detect under physiological conditions, it was induced by heating the cells at $42^{\circ} \mathrm{C}$ for $1 \mathrm{~h}$. Cells $\left(1 \times 10^{5}\right.$ cells $\left./ \mathrm{mL}\right)$ were cultured in medium supplemented with $10 \%$ fetal bovine serum for monolayer culture. After $24 \mathrm{~h}$, the culture medium was replaced with medium containing V. album extract $(100 \mu \mathrm{g} / \mathrm{mL})$. After $48 \mathrm{~h}$, heat shock was induced using an incubator maintained at $42^{\circ} \mathrm{C}$ for $1 \mathrm{~h}$ for heat-shocked groups. After a 6-h recovery period with fresh medium at $37^{\circ} \mathrm{C}$, the cells were harvested (Zhang et al., 2001). 


\section{Extraction of soluble proteins}

The cells were homogenized with lysis buffer containing $2 \mathrm{mM}$ Tris- $\mathrm{HCl}, \mathrm{pH} 6.8,1$ $\mathrm{mM}$ ethylenediaminetetraacetic acid, $1 \%$ Triton X-100, $1 \mathrm{mM}$ phenylmethanesulfonylfluoride, and protease inhibitor cocktail. The extract was centrifuged at $12,000 \mathrm{~g}$ for $20 \mathrm{~min}$ at $4{ }^{\circ} \mathrm{C}$ to remove insoluble materials. The protein concentration of the supernatants was determined using the Bradford assay.

\section{Polyacrylamide gel electrophoresis and Western blot analyses}

For sodium dodecyl sulfate (SDS) polyacrylamide gel electrophoresis and Western blot analysis, protein extracts were denatured in sample buffer containing $25 \mathrm{mM}$ Tris- $\mathrm{HCl}$, pH 6.8, 2\% SDS, 10\% glycerol, 10\% 2-mercaptoethanol, and $0.002 \%$ bromophenol blue and boiled for 3 min. Equal amounts of protein $(20 \mu \mathrm{g} /$ well) were analyzed with $10 \%$ SDS polyacrylamide gel electrophoresis. After electrophoresis, proteins were transferred to polyvinylidene fluoride or nitrocellulose membranes using a BIO-RAD Semi-Dry apparatus. Membranes were blocked with $5 \%$ nonfat dry milk (in Tris-buffered saline-Tween 20 ) at room temperature for $1 \mathrm{~h}$. Primary antibodies against the $\beta, \varepsilon, \eta$, and $\zeta$ isoforms of 14-3-3 proteins were used at $1: 2000,14-3-3 \gamma$ at 1:3000, and anti-Hsp27 at 1:500 for $1 \mathrm{~h}$ at room temperature. Peroxidaseconjugated goat anti-mouse secondary antibodies (for Hsp27) were used at 1:5000, and sheep anti-rabbit secondary antibodies (for anti-14-3-3 antibodies) were used at 1:3000 for $1 \mathrm{~h}$ at room temperature. Protein bands were detected by incubating the membranes with ECL-Plus. Quantitative protein levels were evaluated with the Quantity One software (BIO-RAD).

\section{Determination of caspase- 3 activity}

Caspase-3 activity was measured using the Caspase-3 Colorimetric Activity Assay Kit according to the manufacturer protocol. Briefly, cells were resuspended in cell lysis buffer and incubated on ice for $10 \mathrm{~min}$. At the end of the incubation, cell lysates were centrifuged at $10,000 \mathrm{~g}$ for $5 \mathrm{~min}$ at $4^{\circ} \mathrm{C}$. The supernatants were incubated with $1 \mathrm{mM}$ caspase- 3 substrate (Ac-DEVD-pNA) for $2 \mathrm{~h}$ at $37^{\circ} \mathrm{C}$, and caspase- 3 activity was measured at $405 \mathrm{~nm}$ using a microplate reader. The experiments were performed in triplicate with 3 independent determinations.

\section{Statistical analysis}

Data are given as means \pm standard deviation with $n$ denoting the number of experiments. Statistical comparisons were made using the one-way analysis of variance module of GraphPad Prism 5. Differences in mean values were considered to be significant when the $P$ value was $<0.05$.

\section{RESULTS}

\section{Cytotoxic activity of $V$. album extract}

To investigate the cytotoxic activity of $V$. album extract, we evaluated its effect on a 
C6 glioma cell line with MTT assay. Cytotoxicity data are presented as mean percentages of control \pm standard deviation, and linear regression analysis was used to calculate the half-maximal inhibitory concentration. As illustrated in Figure 1, the $V$. album methanolic extract exhibited cytotoxic activity against C6 glioma cells (half-maximal inhibitory concentration $=270 \mu \mathrm{g} / \mathrm{mL}$ ). At concentrations lower than $100 \mu \mathrm{g} / \mathrm{mL}$ the extract enhanced the relative viability. These results showed that an extract concentration of 100 $\mu \mathrm{g} / \mathrm{mL}$ had no effect on C6 glioma cells. Thus, we used this concentration for further treatment.

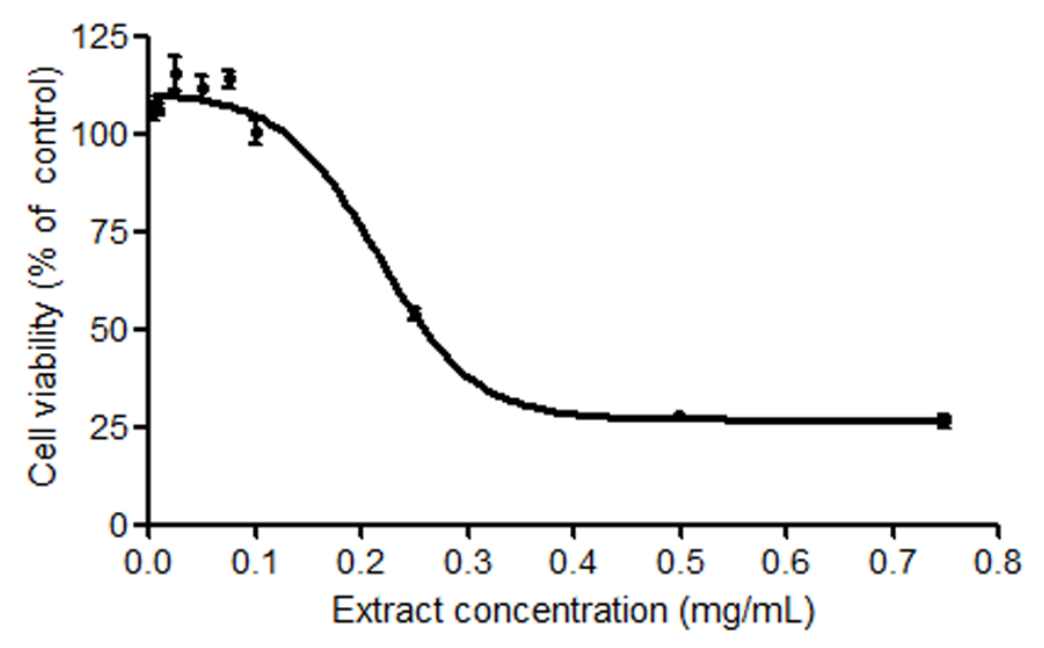

Figure 1. Cytotoxic effect of methanolic extract of Viscum album on C6 glioma cells. Data are reported as means $\pm \mathrm{SD}$ of percent changes compared with untreated controls $(\mathrm{N}=12), \mathrm{R}^{2}=0.62$.

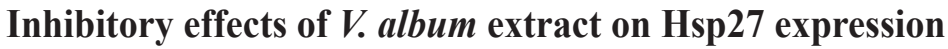

To determine the effect of thermal stress on Hsp27 protein expression, we incubated C6 glioma cells at various temperatures $\left(37^{\circ}-46^{\circ} \mathrm{C}\right)$ for $1 \mathrm{~h}$ and allowed the cells to recover for $6 \mathrm{~h}$ before Western blot analysis. A maximum level of expression was detected after heat shock at $42^{\circ} \mathrm{C}$ (data not shown). Results similar to those reported earlier for Hsp27 in C6 glioma cells were obtained (Zhang et al., 2001).

Western blot analysis showed that the expression of Hsp27 decreased drastically when cells were pretreated with $V$. album methanolic extract before heat shock. A representative Western blot result is shown in Figure 2. Exposure of C6 cells to heat shock resulted in the induction of Hsp27 expression by about $40 \%$ compared that of cells not treated with heat shock. Hsp27 level decreased to $73 \%$ of the control level in extract- and heat-shock-treated cells compared with levels in cells that were only heat shocked (see Figure 2). 


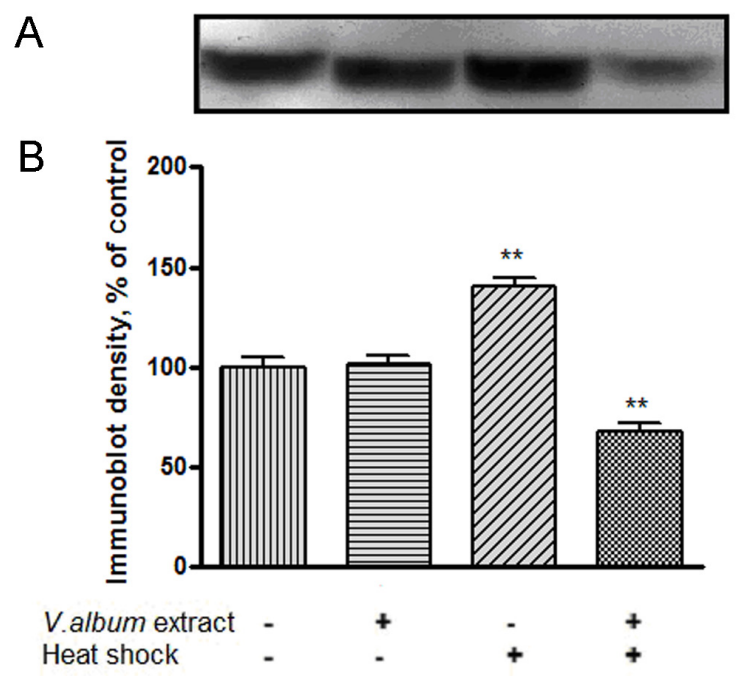

Figure 2. A. Western blot analysis of Hsp27 in C6 glioma cells. For each lane, $20 \mu \mathrm{g}$ protein of crude lysate was loaded and subjected to SDS-PAGE. B. The y-axis indicates the band intensities defined by the number of pixels under each peak $(\mathrm{N}=7, * * * \mathrm{P}<0.001)$.

\section{Inhibitory effects of $V$. album extract on 14-3-3 protein expression}

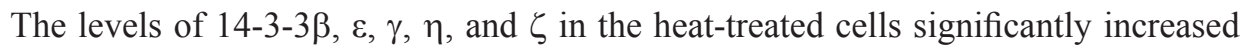
compared to those in untreated cells (Figure 3 ). Compared with protein expression in cells that were only heat shocked, that in cells treated with mistletoe extract displayed protein expression decreases of $124 \%$ for $14-3-3 \beta, 19 \%$ for $14-3-3 \varepsilon, 23 \%$ for $14-3-3 \gamma, 30 \%$ for $14-3-3 \eta$, and $84 \%$ for $14-3-3 \zeta$. The inhibition of the expression of the $\beta, \gamma$, and $\zeta$ isoforms by $V$. album extract was statistically significant (Figure 4).

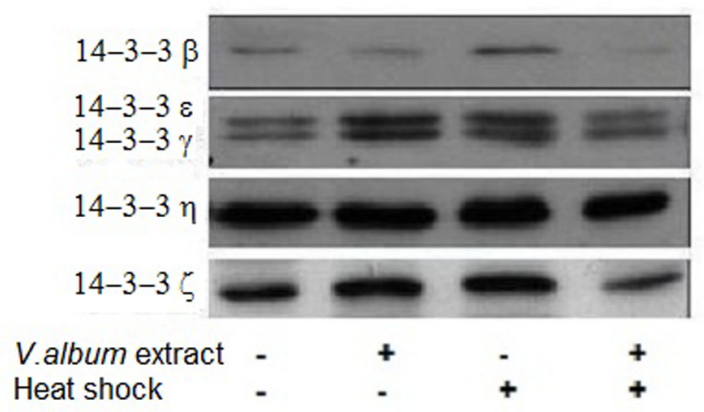

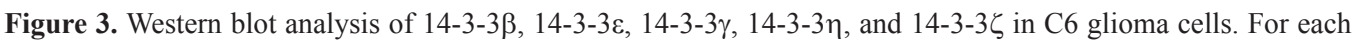
lane, $20 \mu \mathrm{g}$ protein crude lysate was loaded and subjected to SDS-PAGE followed by Western blot as described in Methods. 
E.Ö. Uçar et al.

2808
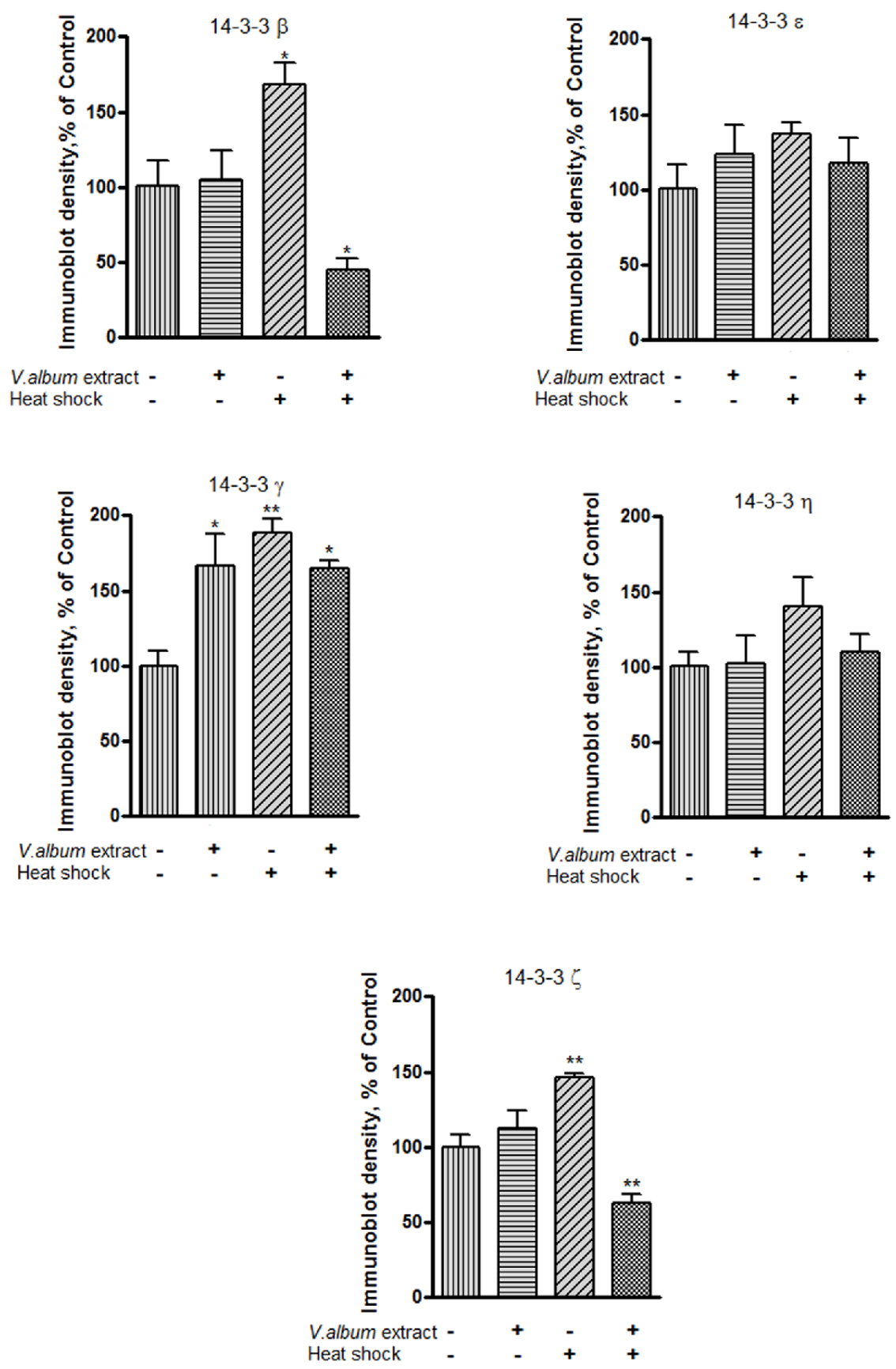

Figure 4. 14-3-3 Protein expression patterns in glioma cells. The y-axis indicates the band intensities defined by the number of pixels under each peak (statistical analysis was performed using one-way ANOVA, $\mathrm{N}=5, * \mathrm{P}<0.05$, $* * \mathrm{P}<0.01)$. 


\section{Induction of apoptosis by $V$. album extract}

Caspase-3 activity was used to estimate apoptosis induction in C6 glioma cells related to $V$. album extract and heat shock. The results in Figure 5 show that the extract significantly induced caspase- 3 activity by $54 \%$ compared with that in control cells. Caspase- 3 activity was increased by approximately $60 \%$ in cells that were treated with both extract and heat shock compared with that in cells treated with heat shock only (see Figure 5, columns 3 and 4). However, heat shock itself had a lower effect on the induction of apoptosis in C6 glioma cells (see Figure 5, column 3).

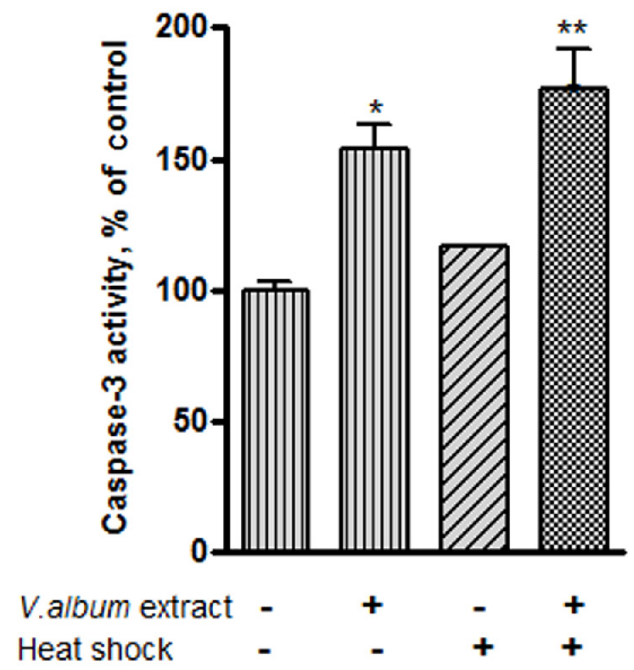

Figure 5. Caspase- 3 activity in C6 glioma cells. Induction of caspase- 3 activity was measured as described in the methods (statistical analysis was performed using one-way ANOVA, $\mathrm{N}=3,{ }^{*} \mathrm{P}<0.05,{ }^{*} \mathrm{P}<0.01$ ).

\section{DISCUSSION}

Hsps are overexpressed in all organisms as well as in many tumor cells to protect them from environmental stresses such as heat, oxidative stress, and ischemia. Elevated Hsp levels in tumor cells are suggested to be responsible for increased chemotherapy resistance and poor prognosis (Garrido et al., 2006; Didelot et al., 2007).

The cytoprotective effects of Hsp27 result from its chaperone function, direct interference with caspase activation, modulation of oxidative stress, and regulation of the cytoskeleton (Liang and MacRea, 1997; Parcellier et al., 2006). Recently, overexpression of Hsp27 in human prostate cancer has been shown to provide resistance to apoptosis and chemotherapy (Andrieu et al., 2010). Garrido et al. (2006) and Parcellier et al. (2006) have also found that increased Hsp27 levels protect prostate cancer cells by increasing tumor proliferation and decreasing apoptosis, thereby facilitating tumor progression. Recently, Hsp27 antisense oligodeoxynucleotides and short interfering RNA have been reported to potently inhibit Hsp27 expression in human prostate PC-3 cells with increased caspase- 3 cleavage, apoptosis, and 
suppression of cell growth (Rocchi et al., 2006). Targeting Hsp27 with antisense oligodeoxynucleotides inhibited Hsp27 expression and enhanced drug sensitivity in several xenograft models (Kamada et al., 2007). Based on these reports and our current data, we speculated about whether the lower expression of Hsp27 in glioma cells could regulate cell death.

Conversely, many studies have reported involvement of 14-3-3 proteins in neurodegenerative diseases, including Creutzfeldt-Jakob disease, cerebrovascular disease, Parkinson disease, malignant brain tumors, and metabolic encephalopathy (Hermeking, 2003; Aitken, 2006). These proteins can function by inhibiting cell death caused by other factors or apoptotic regulators (van Hemert et al., 2001).

In normal brain tissue, 14-3-3 isoforms are localized mainly in the neurons, whereas

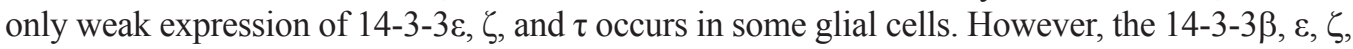
$\eta$, and $\tau$ isoforms are seen in the majority of human astrocytoma samples, and their expression levels are increased markedly by increased pathologic grade. Thus, $14-3-3 \beta$ and $\eta$ proteins may be useful as markers for astrocytoma diagnosis and targets for future therapy (Cao et al., 2008). Proteomic analysis has detected upregulation of 14-3-3 $\beta$ and $\eta$ in human glioma. The expression level of the other main isoforms expressed in brain-14-3-3e, $\gamma$, and $\theta / \tau$-was similar in human glioma and paracancerous brain tissues. These results indicated that the 14-3-3 $\beta$ and $\eta$ isoforms may also play important roles in the tumorigenesis of human gliomas (Liang et al., 2009).

The 14-3-3 $\zeta$ isoform is overexpressed in lung cancer. Downregulation of $14-3-3 \zeta$ has been shown to be critical in anoikis sensitivity in lung cancer (Li et al., 2008). This role of 14$3-3 \zeta$ in tumorigenesis occurs through a mechanism in which anchorage-independent growth of lung cancer cells requires the presence of the 14-3-3 $\zeta$ isoform specifically, which identifies $14-3-3 \zeta$ as a potential molecular target for anticancer therapeutic development.

In the present study we examined the effect of antioxidant $V$. album extract on the induction of Hsp27 and 14-3-3 proteins after heat treatment in C6 cells. This experiment was carried out for the first time to determine the effect of $V$. album methanolic extract on the expression levels of Hsp27 and 14-3-3 proteins in C6 glioma cells. Expression levels were analyzed with Western blot. Our results, based on 2 independent experiments using $V$. album extract alone and in combination with $1 \mathrm{~h}$ of hyperthermia $\left(42^{\circ} \mathrm{C}\right)$, indicated that $\mathrm{Hsp} 27$ and 14-3-3 proteins were induced by heat shock (see Figures 2 and 4). The results also revealed that Hsp27 level was unaltered in cells pretreated with $V$. album extract, whereas heat-shocked cells showed Hsp27 protein expression 1.4-fold higher than that in control cells (see Figure 2).

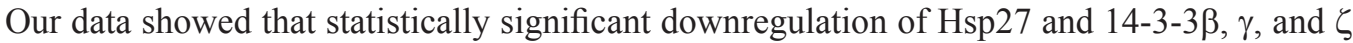
isoforms occurred after $V$. album methanolic extract treatment. In addition, we showed that $V$. album methanolic extract induced apoptosis in C6 glioma cells through caspase-3 activation. Caspase- 3 activity was not altered in heat-shocked cells, although a 1.5 -fold increase in activity in cells pretreated with the extract was detected. In extract- and heat-shock-treated cells, caspase-3 activity was increased approximately 1.6-fold compared with that in cells that were only heat shocked (see Figure 5).

The association between 14-3-3 proteins and Hsps have been studied previously. HspB6 interacts with 14-3-3 proteins in a phosphorylation-dependent manner and affects interaction of 14-3-3 proteins with other binding partners, including protein phosphatases, kinases, and actin-binding proteins that participate in the reorganization of the actin cytoskeleton. HspB6 may also regulate the activity of protein kinases, which is also dependent on HspB6 phosphorylation. This activity may in turn be regulated by the formation of het- 
erooligomeric complexes of HspB6 with other small Hsps (Seit-Nebi and Gusev, 2010).

Various $V$. album extracts are widely used as complementary cancer therapies in Europe (Zarkovic et al., 2001; Ernst et al., 2003), and the extract of $V$. album is known to have antioxidant activity (Önay-Uçar et al., 2006). The antioxidant activity of the plant products is associated with their bioactive compounds, mainly antioxidant phenolics, owing to their ability to scavenge free radicals. Also, flavonols exhibit numerous biological and pharmacological effects, including antioxidant, chelation, and anticarcinogenic effects. Evidence suggests that the pharmacological effects of flavonoids are correlated with their antioxidant activity (Harwood et al., 2007).

Certain antioxidant compounds such as pyrrolidine dithiocarbamate and phenanthroline are known to prevent Hsp gene induction, and the combination of antioxidant treatment with exposure to heat stress leads to cell death (Gorman et al., 1999). In addition, many studies have demonstrated that some flavonoids exhibit a synergistic antitumor effect with chemotherapeutics (Cipak et al., 2003; Jakubowicz-Gil et al., 2005). Quercetin sensitizes HeLa cells to cisplatin and increases the level of apoptosis. The significant decrease in Hsp27 and Hsp72 expression after quercetin treatment correlates with the highest sensitivity of HeLa cells to cisplatin-induced apoptosis (Jakubowicz-Gil et al., 2005).

The mechanism of downregulation of Hsp27 by quercetin is not clearly understood. One possible explanation is that quercetin inhibits Hsp expression at the level of transcription, preventing heat shock factor 1 and 2 from binding to the conserved DNA sequence known as the heat shock element in the promoter region of Hsp genes. Other studies have indicated that quercetin acts during early steps of Hsp synthesis by blocking additional modifications, such as phosphorylation, necessary for the activation of heat shock factors or by causing conformational changes in the factors and inhibiting their interaction with other DNA-binding proteins in the promoter region (Jakubowicz-Gil et al., 2002).

In $V$. album methanolic extract, the total quercetin content has been measured at 4.92 $\mathrm{mg} / \mathrm{g}$ crude extract, which is higher than that in black tea $(1.07 \mathrm{mg} / \mathrm{g}$ crude extract) (data not shown). Thus, the high quercetin content in $V$. album extract may be responsible for decreases in Hsp27 and 14-3-3 expression and the induction of apoptosis in C6 glioma cells.

Inhibitors of Hsps in concert with classical chemotherapy increase the sensitivity of cancer cells to cytotoxic drugs. Some Hsps (Hsp90, Hsp70, and Hsp27) can directly interact with various proteins related to apoptosis and thereby block the apoptotic process at key points (Didelot et al., 2007). In cancer cells, in which the expression of Hsps is frequently abnormally high, they participate in oncogenesis and resistance to chemotherapy (Garrido et al., 2006; Didelot et al., 2007; Zhu et al., 2010). Therefore, the inhibition of Hsps has become an interesting approach to the development of cancer therapy strategies.

Expression of Hsp27 and 14-3-3 proteins is clearly upregulated in some cancer types, and these proteins may play important roles in the response of cancer cells to drug and other therapeutic treatments. These proteins may also serve as prognostic markers for predicting survival in cancer patients. Future studies targeting these proteins for the development of chemosensitizers may improve cancer treatment through combinational therapy.

\section{ACKNOWLEDGMENTS}

Research supported by the Istanbul University Research Foundation, Turkey (\#T-746/13092005 and \#18892). 


\section{REFERENCES}

Aitken A (2006). 14-3-3 proteins: a historic overview. Semin. Cancer Biol. 16: 162-172.

Andrieu C, Taieb D, Baylot V, Ettinger S, et al. (2010). Heat shock protein 27 confers resistance to androgen ablation and chemotherapy in prostate cancer cells through eIF4E. Oncogene 29: 1883-1896.

Arrigo AP (2007). Anti-Apoptotic, Tumorigenic and Metastatic Potential of Hsp27 (HspB1) and $\alpha$ B-crystallin (HspB5): Emerging Targets for the Development of New Anti-Cancer Therapeutic Strategies. In: Heat Shock Proteins in Cancer (Calderwood SK, Sherman MY and Ciocca DR, eds.). Springer, New York, 73-92.

Büssing A and Schietzel M (1999). Apoptosis-inducing properties of Viscum album L. extracts from different host trees, correlate with their content of toxic mistletoe lectins. Anticancer Res. 19: 23-28.

Cao L, Cao W, Zhang W, Lin H, et al. (2008). Identification of 14-3-3 protein isoforms in human astrocytoma by immunohistochemistry. Neurosci. Lett. 432: 94-99.

Cao WD, Zhang X, Zhang JN, Yang ZJ, et al. (2006). Immunocytochemical detection of 14-3-3 in primary nervous system tumors. J. Neurooncol. 77: 125-130.

Chen XL, Zhou L, Yang J, Shen FK, et al. (2010). Hepatocellular carcinoma-associated protein markers investigated by MALDI-TOF MS. Mol. Med. Rep. 3: 589-596.

Ciocca DR and Calderwood SK (2005). Heat shock proteins in cancer: diagnostic, prognostic, predictive, and treatment implications. Cell Stress Chaperones 10: 86-103.

Cipak L, Novotny L, Cipakova I and Rauko P (2003). Differential modulation of cisplatin and doxorubicin efficacies in leukemia cells by flavonoids. Nutr. Res. 23: 1045-1057.

Didelot C, Lanneau D, Brunet M, Joly AL, et al. (2007). Anti-cancer therapeutic approaches based on intracellular and extracellular heat shock proteins. Curr. Med. Chem. 14: 2839-2847.

Ernst E, Schmidt K and Steuer-Vogt MK (2003). Mistletoe for cancer? A systematic review of randomised clinical trials. Int. J. Cancer 107: 262-267.

Garrido C, Brunet M, Didelot C, Zermati Y, et al. (2006). Heat shock proteins 27 and 70: anti-apoptotic proteins with tumorigenic properties. Cell Cycle 5: 2592-2601.

Gorman AM, Heavey B, Creagh E, Cotter TG, et al. (1999). Antioxidant-mediated inhibition of the heat shock response leads to apoptosis. FEBS Lett. 445: 98-102.

Graner MW and Bigner DD (2005). Chaperone proteins and brain tumors: potential targets and possible therapeutics. Neuro Oncol. 7: 260-278.

Hamad I, Erol-Dayi O, Pekmez M, Önay-Uçar E, et al. (2010). Antioxidant and cytotoxic activities of Aphanes arvensis extracts. Plant Foods Hum. Nutr. 65: 44-49.

Harwood M, Danielewska-Nikiel B, Borzelleca JF, Flamm GW, et al. (2007). A critical review of the data related to the safety of quercetin and lack of evidence of in vivo toxicity, including lack of genotoxic/carcinogenic properties. Food Chem. Toxicol. 45: 2179-2205.

Hermeking H (2003). The 14-3-3 cancer connection. Nat. Rev. Cancer 3: 931-943.

Jakubowicz-Gil J, Rzymowska J and Gawron A (2002). Quercetin, apoptosis, heat shock. Biochem. Pharmacol. 64: 15911595.

Jakubowicz-Gil J, Paduch R, Piersiak T, Glowniak K, et al. (2005). The effect of quercetin on pro-apoptotic activity of cisplatin in HeLa cells. Biochem. Pharmacol. 69: 1343-1350.

Kamada M, So A, Muramaki M, Rocchi P, et al. (2007). Hsp27 knockdown using nucleotide-based therapies inhibit tumor growth and enhance chemotherapy in human bladder cancer cells. Mol. Cancer Ther. 6: 299-308.

Karagöz A, Onay E, Arda N and Kuru A (2003). Antiviral potency of mistletoe (Viscum album ssp. album) extracts against human parainfluenza virus type 2 in Vero cells. Phytother. Res. 17: 560-562.

Li Z, Zhao J, Du Y, Park HR, et al. (2008). Down-regulation of 14-3-3zeta suppresses anchorage-independent growth of lung cancer cells through anoikis activation. Proc. Natl. Acad. Sci. U. S. A. 105: 162-167.

Li Z, Dong Z, Myer D, Yip-Schneider M, et al. (2010). Role of 14-3-3 $\sigma$ in poor prognosis and in radiation and drug resistance of human pancreatic cancers. BMC Cancer 10: 598.

Liang P and MacRae TH (1997). Molecular chaperones and the cytoskeleton. J. Cell Sci. 110: 1431-1440.

Liang S, Shen G, Liu Q, Xu Y, et al. (2009). Isoform-specific expression and characterization of 14-3-3 proteins in human glioma tissues discovered by stable isotope labeling with amino acids in cell culture-based proteomic analysis. Proteomics Clin. Appl. 3: 743-753.

Martin H, Patel Y, Jones D, Howell S, et al. (1993). Antibodies against the major brain isoforms of 14-3-3 protein. An antibody specific for the N-acetylated amino-terminus of a protein. FEBS Lett. 331: 296-303.

Önay-Uçar E, Karagöz A and Arda N (2006). Antioxidant activity of Viscum album ssp. album. Fitoterapia 77: 556-560. 
Parcellier A, Brunet M, Schmitt E, Col E, et al. (2006). HSP27 favors ubiquitination and proteasomal degradation of p27Kip1 and helps S-phase re-entry in stressed cells. FASEB J. 20: 1179-1181.

Rocchi P, Jugpal P, So A, Sinneman S, et al. (2006). Small interference RNA targeting heat-shock protein 27 inhibits the growth of prostatic cell lines and induces apoptosis via caspase-3 activation in vitro. BJU Int. 98: 1082-1089.

Seit-Nebi AS and Gusev NB (2010). Versatility of the small heat shock protein HSPB6 (Hsp20). Cell Stress Chaperones 15: 233-236.

van Hemert MJ, Steensma HY and van Heusden GP (2001). 14-3-3 proteins: key regulators of cell division, signalling and apoptosis. BioEssays 23: 936-946.

Yano M, Nakamuta S, Wu X, Okumura Y, et al. (2006). A novel function of 14-3-3 protein: 14-3-3 3 is a heat-shockrelated molecular chaperone that dissolves thermal-aggregated proteins. Mol. Biol. Cell 17: 4769-4779.

Zarkovic N, Vukovic T, Loncaric I, Miletic M, et al. (2001). An overview on anticancer activities of the Viscum album extract Isorel. Cancer Biother. Radiopharm. 16: 55-62.

Zhang R, Tremblay TL, McDermid A, Thibault P, et al. (2003). Identification of differentially expressed proteins in human glioblastoma cell lines and tumors. Glia 42: 194-208.

Zhang WL, Tsuneishi S and Nakamura H (2001). Induction of heat shock proteins and its effects on glial differentiation in rat C6 glioblastoma cells. Kobe J. Med. Sci. 47: 77-95.

Zhu Z, Xu X, Yu Y, Graham M, et al. (2010). Silencing heat shock protein 27 decreases metastatic behavior of human head and neck squamous cell cancer cells in vitro. Mol. Pharmacol. 7: 1283-1290. 